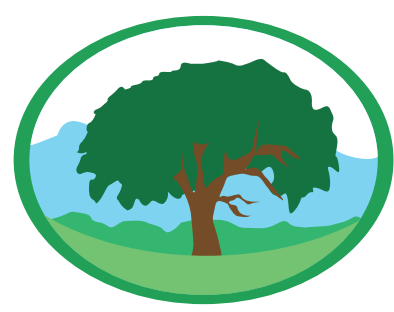

\title{
MICRORREVESTIMENTO ASFÁLTICO A FRIO: PROPOSTAS PARA MELHORIA NO PROCESSO DE CONTROLE E EXECUÇÃO
}

\author{
COELHO, H. 0. ${ }^{1}$; HALLAL, R. R. ${ }^{1}$; SOUZA, R. M. ${ }^{2}$; MARTINS, M. F. ${ }^{3}$; SPECHT, L. P. ${ }^{4}$; PEREIRA, D. S. ${ }^{5}$. \\ 'Mestre em Engenharia (UFRGS), Analista de Infraestrutura (DNIT), Professor Assistente do Curso de Engenharia Civil (UFPel) \\ ${ }^{2}$ Engenheira Civil \\ ${ }^{3}$ Mestrando do Programa de Pós-Graduação em Eng. Civil (UFSM) \\ ${ }^{4}$ Dr. em Engenharia (UFRGS), Professor Adjunto do Curso de Engenharia Civil e do Programa de Pós-Graduação em Engenharia \\ Civil (UFSM) \\ ${ }^{5}$ Dr. em Engenharia de Transportes (USP), Professor Adjunto do Curso de Engenharia Civil e do Programa de Pós-Graduação \\ em Engenharia Civil (UFSM)
}

Palavras-chave: conservação, rodovia, variáveis

\begin{abstract}
Resumo
0 microrrevestimento asfáltico a frio, por tratar-se de uma solução economicamente viável e de fácil aplicação, vem sendo utilizado constantemente em obras de manutenção e conservação de rodovias. Porém, como nem sempre os locais e condições de aplicação são ideais, os métodos de controle e execução do microrrevestimento não são suficientes para obter-se o desempenho ideal da mistura. Neste contexto, o presente estudo apresenta um levantamento sobre as variáveis que influenciam na aplicação do microrrevestimento, identificadas a partir da execução do mesmo em um trecho da rodovia BR-293 e de estudos realizados juntamente com empresas ligadas a este tipo de serviço, visando identificar como essas variáveis interferem no desempenho da mistura e assim, propor melhorias no processo de controle e execução. Pelo fato de existirem muitas variáveis que podem interferir diretamente no desempenho do microrrevestimento, pode-se afirmar tranquilamente que ainda há necessidade de realização de muitas outras pesquisas relacionadas com a utilização dessa solução, para que se tenha maior segurança em relação às potencialidades desse tipo de revestimento e para que se possa realizar o controle de sua execução de forma eficaz e eficiente.
\end{abstract}

\section{MICROSURFACING: PROPOSALS FOR IMPROVEMENT IN THE CONTROL AND EXECUTION PROCESS}

Keywords: conservation, highway, variables

\begin{abstract}
The microsurfacing, as it is an economically feasible solution and easy to apply, is constantly being used in road maintenance and maintenance works. However, as the locations and conditions of application are not always ideal, the methods of control and execution of microsurfacing are not sufficient to obtain optimum mixing performance. In this context, the present study presents a survey on the variables that influence the application of microsurfacing, identified from the execution in a section of highway BR-293 and studies carried out together with companies related to this type of service, aiming to identify as these variables interfere in the performance of mixture and thus propose improvements in the control and execution process. Because there are many variables that can interfere directly in the performance of microsurfacing, it can be said quietly that there is still the need to carry out other research related to this solution, so that it has more security in relation to the potentialities of this kind of coating and so that it can perform the control effectively and efficiently.
\end{abstract}




\section{INTRODUÇÃO}

Atualmente, a nível mundial, o Microrrevestimento Asfáltico a Frio (MRAF) tem sido uma das técnicas mais utilizadas em serviços de conservação preventiva de rodovias (ROBATI et al., 2015; POURSOLTANI et al., 2017; SIMÓES et al., 2017). Conforme Yang e Liu (2017), o MRAF é uma mistura asfáltica aplicada a frio, constituída de agregado miúdo, fíler, emulsão asfáltica modificada por polímero elastomérico, água, aditivos se necessário, projetada para ser aplicada em consistência fluida com o uso de usina móvel. Sistema derivado da lama asfáltica, o MRAF surgiu na Europa, em meados dos anos 1970, e foi introduzido nos Estados Unidos na década de 1980 (BROUGHTON et al., 2012). Desde então, a técnica difundiu-se rapidamente por diversos países ao redor mundo (KUMAR; RYNTATHIANG, 2016).

No Brasil, o MRAF é utilizado desde a década de 1990 e seu principal campo de aplicação é na conservação de pavimentos que necessitam rejuvenescimento e melhoria das condiçôes de aderência pneu-pavimento e não apresentam problemas estruturais (ABEDA, 2010; CERATTI et al., 2015; APAZA; GUIMARÃES, 2016; LUZZI, 2017). O MRAF apresenta algumas vantagens, tais como: exige pouca energia e é ecoeficiente (GUJAR et al., 2013); permite rápida abertura ao tráfego (LABI et al., 2007); funciona bem em rodovias de baixo, médio e alto volume de tráfego (WATSON; JARED, 1998); entre outras. Nesse contexto, o presente estudo apresenta um levantamento sobre as variáveis que influenciam na aplicação do MRAF, identificadas a partir da execução do mesmo em um segmento de pista da rodovia BR293 e de estudos realizados juntamente com empresas ligadas a este tipo de serviço, visando identificar como essas variáveis interferem no desempenho da mistura e, assim, propor melhorias no processo de controle e execução do MRAF.

\section{MATERIAL E MÉTODOS}

$\mathrm{O}$ presente trabalho trata-se de uma pesquisa experimental, do tipo estudo de caso, que foi realizada em um segmento de pista da rodovia BR-293. Foram realizadas vistorias e observaçóes de campo, coleta e ensaios de amostras, registros fotográficos e filmagens dos métodos executivos, além de entrevistas com a equipe técnica da obra.

A rodovia em questão foi escolhida por possuir contrato de manutenção e conservação com o Departamento Nacional de Infraestrutura de Transportes (DNIT), no qual uma das soluçóes previstas de recuperação da pista é a aplicação de duas camadas de MRAF, resultando em uma espessura final de $15 \mathrm{~mm}$. A Figura 1, a seguir, ilustra as duas camadas de MRAF executadas sobre o pavimento do segmento estudado.

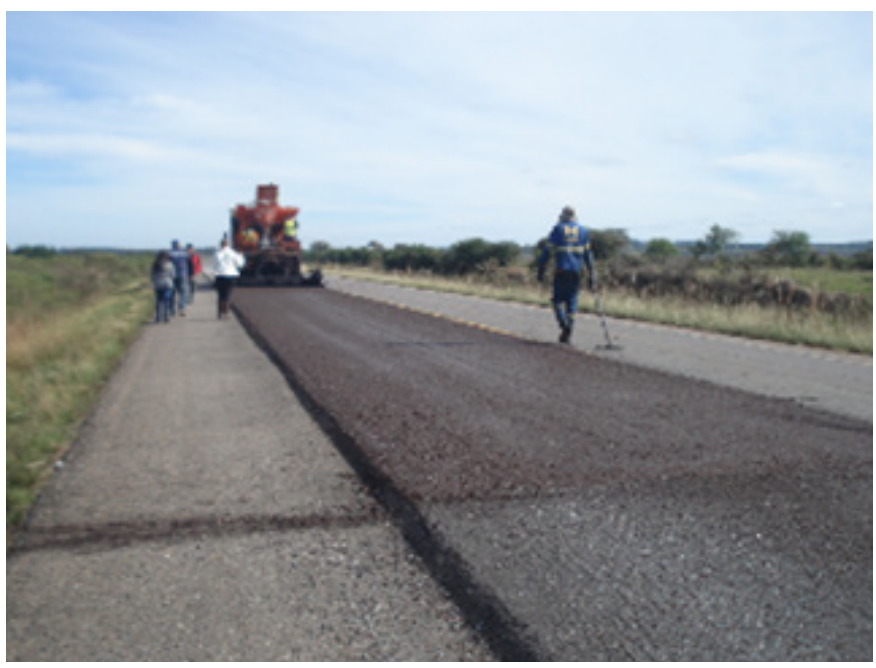

Figura 1. Camadas de MRAF executadas sobre o pavimento do segmento estudado. Fonte: Autores

A emulsão empregada no MRAF em questão foi uma emulsão RC-1C E, isto é, uma emulsão de ruptura controlada. Segundo o projeto proposto pela empresa responsável pela execução do serviço na rodovia, o teor de ligante asfáltico residual era de 5,9\% (em peso de agregado seco) e o teor de emulsão, de 9,5\%.

A composição granulométrica da mistura de agregados do MRAF empregado neste estudo foi composta por pedrisco (brita 3/8") e pó de pedra (material passante na peneira número 200), atendendo a faixa II (Tabela 1) da norma DNIT 035/2005ES (DNIT, 2005), norma rodoviária que orienta a execução dos serviços de MRAF no Brasil. Essa faixa granulométrica, por sua vez, é indicada para rodovias de tráfego pesado, condição que pode ser observada na BR-293. 
Tabela 1. Faixa II da norma DNIT 035/2005-ES

\begin{tabular}{cccc}
\hline Peneira & $\begin{array}{l}\text { Abertura } \\
(\mathrm{mm})\end{array}$ & $\begin{array}{l}\text { Peso passante } \\
\text { na Faixa II } \\
(\%)\end{array}$ & $\begin{array}{l}\text { Tolerância } \\
\text { da curva de } \\
\text { projeto (\%) }\end{array}$ \\
\hline 1/2” & 12,50 & - & - \\
$3 / 8 ”$ & 9,50 & 100,00 & $\pm 5,00$ \\
No 4 & 4,75 & $70,00-90,00$ & $\pm 5,00$ \\
No 8 & 2,36 & $45,00-70,00$ & $\pm 5,00$ \\
No 16 & 1,18 & $28,00-50,00$ & $\pm 5,00$ \\
No 30 & 0,60 & $19,00-34,00$ & $\pm 5,00$ \\
No 50 & 0,33 & $12,00-25,00$ & $\pm 5,00$ \\
No 100 & 0,15 & $7,00-18,00$ & $\pm 3,00$ \\
No 200 & 0,075 & $5,00-15,00$ & $\pm 2,00$ \\
\hline
\end{tabular}

Embora a responsabilidade técnica pela execução dos serviços seja da empresa executora, amostralmente o DNIT acompanha a realizaçáo dos ensaios previstos em norma para análise comparativa com o projeto apresentado. Conforme previsto na Especificação de Serviço 035/2005 do DNIT, principal norma brasileira eventualmente podem ser realizados pequenos ajustes na mistura no momento da execução do serviço, utilizando-se material de enchimento (fíler), não plásticos, secos e isentos de grumos. No MRAF em análise, o material de enchimento utilizado foi a cal extinta.

Dessa forma, foi realizado o acompanhamento do processo de execução convencional do MRAF, buscando identificar as variáveis que influenciam a execução e, consequentemente, o desempenho do MRAF. Através do estudo realizado, alguns pontos importantes foram identificados: textura do pavimento; irregularidades pré-existentes na superfície onde foi aplicada a camada de revestimento; umidade do material pétreo; a faixa granulométrica dos agregados; quantidade de água utilizada na mistura; estado de conservação da usina móvel, entre outros. Por fim, foram propostas melhorias nos métodos de execução e controle tecnológico do MRAF, bem como foram identificados os pontos mais críticos do processo executivo que afetam diretamente o desempenho e vida útil do revestimento.

\section{RESULTADOS E DISCUSSÃO}

Durante o acompanhamento realizado, observou-se que o material granular utilizado para a preparação prévia da mistura de MRAF encontravase armazenado/depositado diretamente no chão e com cobertura precária. Nessas condições, além da variação da umidade do material, eventualmente esse material pode vir a misturar-se com impurezas presentes no solo.

Paralelamente, ao acompanhar a etapa de carregamento da mistura para a usina móvel de MRAF, observou-se que não havia um controle rigoroso da quantidade de material que era carregado no caminhão, pois a determinação desta quantidade era feita visualmente, pelo operador da pá carregadeira. Devido a este aspecto, o volume de material carregado não era plenamente controlado, podendo ser bastante variável. Esse procedimento inviabiliza uma forma de controle da espessura da camada de MRAF aplicada, pois, tendo-se conhecimento do volume total carregado na usina móvel e das dimensóes (largura e comprimento) do trecho onde será aplicada a camada, ter-se-ia a dimensão da espessura de material aplicada.

O MRAF é muito empregado em trilhas de roda (onde é indicada uma granulometria mais grossa para garantir atrito/aderência com os pneus dos veículos e para obter uma espessura maior de camada) e em selagem de trincas (onde é indicada uma granulometria mais fina seria mais adequada para que a emulsão penetre nas trincas e faça a selagem das mesmas). Porém, o que é constatado, é que não é usual a consideração das condiçôes de conservação dos segmentos que receberão camada/camadas de MRAF para a definição da faixa granulométrica de trabalho, assim como não é comum a consideração das características do pavimento existente para esta definição.

No estudo de caso utilizou-se material com granulometria enquadrada na faixa II do DNIT para toda a extensão do trecho, náo sendo previstas as variaçóes no pavimento base (textura, presença de fissuras), ou seja, não foi realizada a avaliação prévia das variaçóes da base onde seria aplicado o MRAF. Dessa forma, pode ocorrer a utilização incorreta de granulometrias indicadas em norma para cada tipo de problema. 
A aplicação do MRAF no estudo de caso foi realizada no mês de maio, período em que a temperatura encontra-se relativamente baixa e a umidade do ar alta. Neste período, tem-se também uma incidência mais amena e menos intensa de raios solares.

De acordo com Ceratti e Reis (2011), o MRAF não deve ser executado em temperaturas inferiores a $10^{\circ} \mathrm{C}$ e que estejam caindo, seja do ar ou do pavimento. Os autores recomendam ainda que a formulação da emulsão seja ajustada e/ou utilize-se aditivo líquido para controle do tempo de ruptura, possibilitando a aplicação adequada.

Dessa forma, a empresa executora aguardou que a temperatura ambiente mínima de aplicação do MRAF fosse atingida para realizar a aplicação, porém as demais condiçôes climáticas como, por exemplo, a umidade relativa do ar, podem ter influência no desempenho da mistura.

$\mathrm{O}$ ajuste da consistência do MRAF é realizado regulando-se o volume de água adicionada à mistura, diretamente no caminhão (usina móvel), de forma manual pelo próprio operador no momento da aplicação, após decisão do próprio a partir de uma avaliação visual da mistura, como pode ser visto na Figura 2.

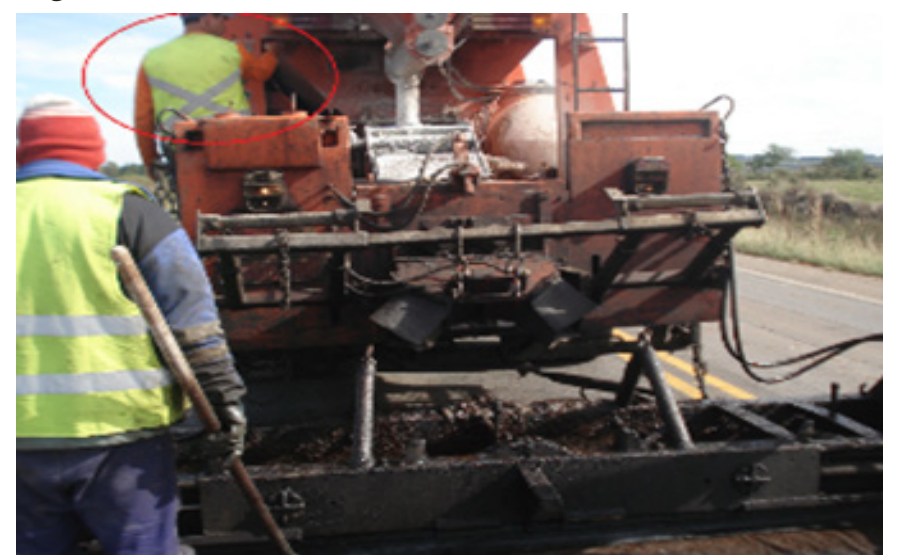

Figura 2. Alimentação de água da mistura na usina de MRAF. Fonte: Autores

Desta forma, verifica-se que não há um controle exato do volume de água que é utilizada na mistura, fazendo com que a taxa de aplicação seja inconstante e desconhecida, baseada somente na sensibilidade e experiência do operador.

Além disso, não se realiza ensaio prévio para análise da umidade do material pétreo para determinar ou servir de parâmetro para a adição de água na mistura.
No caso da adição de elevadas quantidades de água, o que torna a mistura muito líquida, há maior dificuldade para que o equipamento de distribuição transversal realize uma distribuição homogênea da mistura, empurrando para as extremidades uma parte da mistura com maior percentual de material granular, permanecendo no centro o material com maior quantidade de fluído ou emulsão.

Em equipamentos de fabricação recente, há tecnologias desenvolvidas para melhorar este controle através de um equipamento acoplado às usinas móveis, chamado medidor de vazão digital ou rotâmetro. Este instrumento é utilizado para medir e controlar a vazão instantânea de líquidos e gases. A precisão da medição é assegurada por calibração do aparelho para atender as necessidades.

Segundo Ceratti e Reis (2011), a consistência adequada para uma boa trabalhabilidade do MRAF depende, principalmente, da quantidade de água na mistura. Um baixo teor de água resulta em misturas difíceis de espalhar e de baixa adesão ao substrato. Por outro lado, um teor alto tende a provocar a sedimentação dos finos e flotação do ligante asfáltico, resultando em uma superfície altamente lisa e derrapante quando molhada, retardando também a cura do microrrevestimento para liberação ao tráfego.

Observando-se a execução do MRAF, verificou-se que o despejo da mistura a partir do caminhão usina ocorreu somente na região central da mesa distribuidora e foi levada para as extremidades a partir da ação de parafusos helicoidais que preenchem toda a mesa distribuidora com a mistura. A mesa distribuidora é mostrada na Figura 3A e os parafusos helicoidais, na Figura 3B.

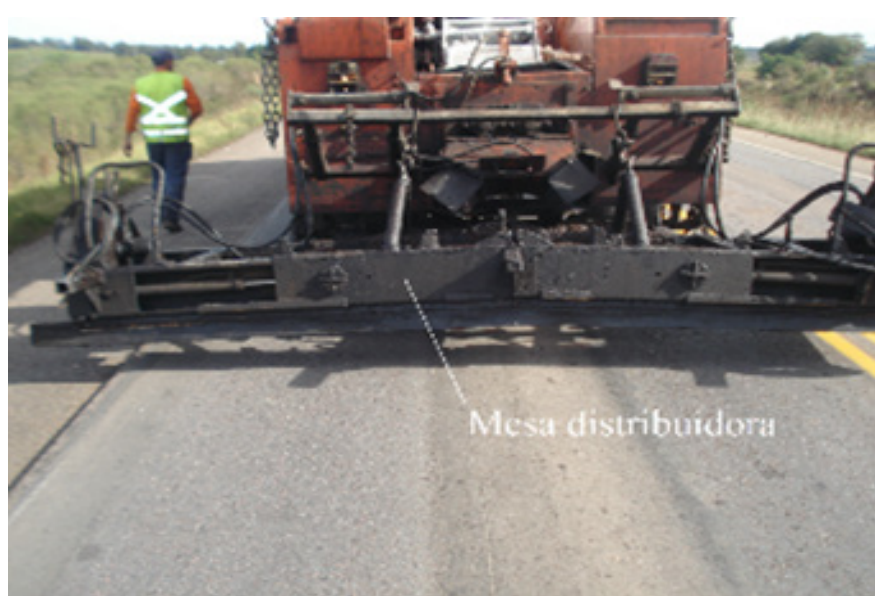

Figura 3A. Mesa distribuidora. Fonte: Autores 


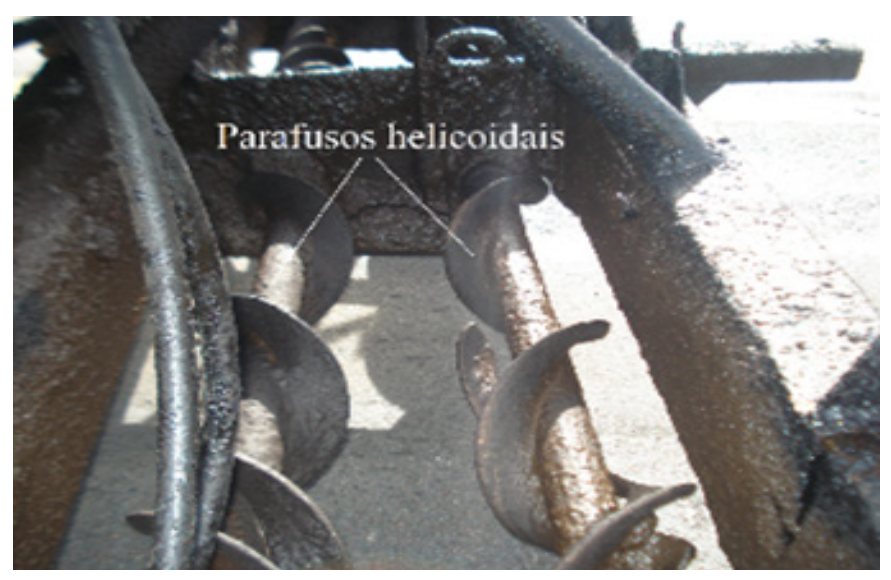

Figura 3B. Parafusos helicoidais. Fonte: Autores

Essa mecânica de distribuição pode ocasionar a segregação transversal do material, pois, devido a presença de um esqui central, com parte apoiada no chão, a mistura tende a preencher o espaço existente atrás do esqui por meio de deslocamentos horizontais. A tendência, nesses deslocamentos, é que a parte líquida da mistura preencha os espaços mais rapidamente que a parte composta pelos agregados. Assim, no momento em que a emulsão rompe, devido à falta de material pétreo nessa localidade, ocorre a formação de um afundamento longitudinal que se forma no eixo da faixa, onde fica localizado o esqui central. O afundamento longitudinal é mostrado na Figura $4 \mathrm{~A}$ e o esqui central, na Figura 4B.

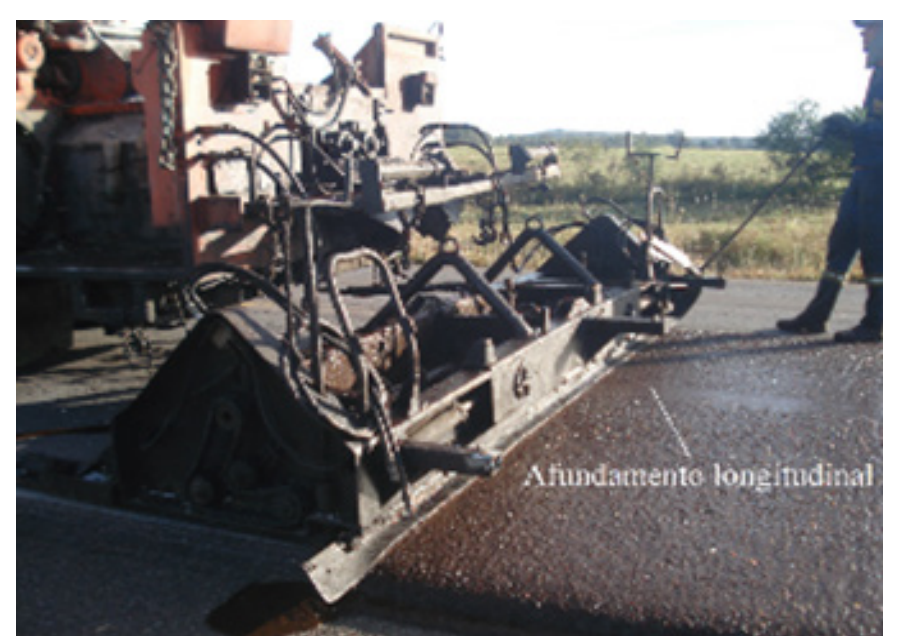

Figura 4A. Afundamento longitudinal. Fonte: Autores

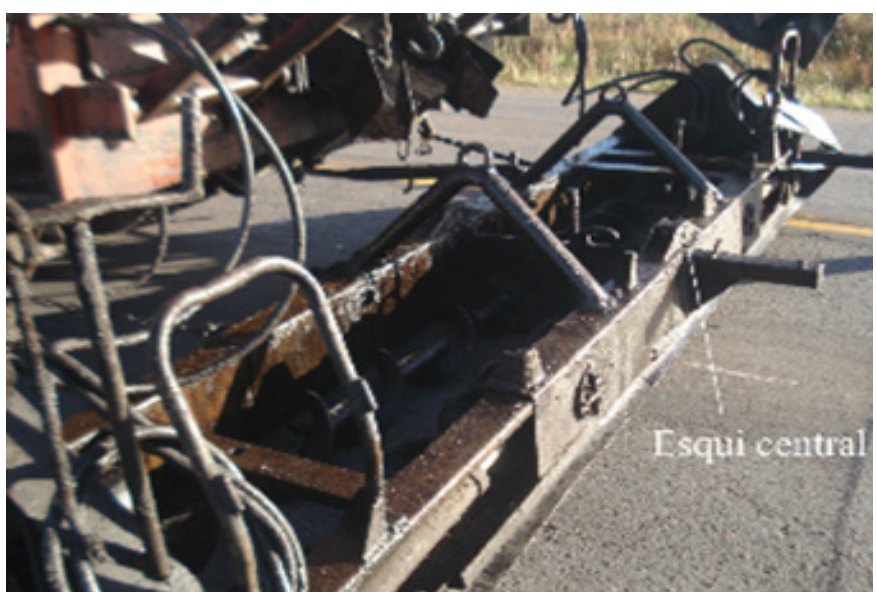

Figura 4B. Esqui central. Fonte: Autores

Além disso, quando há a presença de esqui central na mesa distribuidora pode ocorrer um desalinhamento dos parafusos helicoidais nos dois lados do esqui. Esse alinhamento é essencial para que a mistura não seja distribuída de forma irregular pela mesa e, consequentemente, pela pista.

Além da avaliação de praxe, no momento do recebimento do equipamento a ser utilizado na execução dos serviços, é importante que sempre se faça a calibragem da usina móvel no momento imediatamente anterior a aplicaçáo do MRAF para garantir que o equipamento esteja em pleno funcionamento e adaptado às condiçôes locais de execução e ajustá-lo adequadamente sempre que necessário.

No trecho estudado, verificou-se que foi realizado este procedimento antes do início da primeira aplicação de MRAF, porém sugere-se que esta calibragem seja refeita a cada parada e reinício da execução. Além disso, seria adequado fazer a calibragem sempre que houvessem alteraçôes climáticas, alterações no pavimento base (tipo de pavimento, textura, nível de desgaste) e quaisquer mudanças que possam influenciar na aplicação.

Outro aspecto levantado e de grande importância refere-se ao estado de conservação do equipamento, devido à influência que este pode ter na mistura. Nessa avaliação, deve-se observar o grau de desgaste dos parafusos helicoidais responsáveis pelo espalhamento da mistura ao longo da mesa de aplicação. Quando há excessivo desgaste desses parafusos, a distribuição da mistura não se dá de forma homogênea. 
Atualmente, há mudanças relevantes na fabricação das usinas móveis e também das mesas distribuidoras. Esta diferença entre equipamentos mais antigos e os equipamentos fabricados recentemente (com toda tecnologia necessária para um bom desempenho da mistura asfáltica) têm grande impacto sobre a execução e, provavelmente, sobre o comportamento do MRAF em serviço.

Outra particularidade refere-se ao estado de conservação da borracha de nivelamento, que proporciona o acabamento final da superfície aplicada. É perceptível que uma borracha nova apresenta rigidez mais elevada em relação a uma borracha desgastada, desse modo possui maior propensão ao arraste de material pétreo e de comprimir a mistura sobre a pista, isto pode influenciar diretamente na espessura de MRAF aplicada. Ceratti e Reis (2011) ressaltam que deve ser dada atenção à manutenção de rotina da usina móvel, de acordo com as recomendaçóes do fabricante, pois impactam diretamente na qualidade final dos serviços, tais como: limpeza diária do misturador e da caixa distribuidora no período da aplicação entre um carregamento e outro (limpeza das borrachas e remoção de material interno, regulagem de altura das roscas em relação à altura dos esquis, pressão das borrachas ao solo, dureza das borrachas de corte e nivelamento da caixa distribuidora ao solo).

\section{CONCLUSÃO}

Com a realização deste trabalho, percebeu-se que estudar o comportamento do MRAF torna-se cada vez mais pertinente, visto que os métodos de controle preconizados na Especificação de Serviço 035/2005 do DNIT são de difícil aplicação e não estão relacionados diretamente com o desempenho dessa solução.

Além do mais, considerando que os resultados aqui apresentados são inferências levantadas acerca das variáveis que foram identificadas neste estudo de caso, ressalta-se que seria de fundamental importância a realização de novos estudos, visando comprovar tais hipóteses.

Portanto, pelo fato de existirem muitas variáveis que podem interferir diretamente no desempenho do MRAF, pode-se afirmar tranquilamente que ainda há necessidade de realizaçáo de muitas outras pesquisas relacionadas com a utilização dessa solução, para que se tenha maior segurança em relação às potencialidades desse tipo de revestimento e para que se possa realizar o controle de sua execuçáo de forma eficaz e eficiente.

\section{LITERATURA CITADA}

APAZA, F. R. A.; GUIMARĀES, A. C. R. Análise da viabilidade técnica da utilização do resíduo beneficiamento do minério de ferro em microrrevestimento asfáltico. Revista Pavimentação, v. 40, p.49-66, 2016.

BROUGHTON, B.; LEE, S. J.; KIM, Y. J. 30 years of microsurfacing: a review. ISRN Civil Engineering, v. 2012, p.17, 2012.

CERATTI, J. A. P.; BERNUCCI, L. B.; SOARES, J. B. Utilização de ligantes asfálticos em serviços de pavimentação. 1. ed. Rio de Janeiro: Abeda, 2015. 144p.

CERATTI, J. A. P.; REIS, R. M. M. Manual de microrrevestimento asfáltico a frio - MRAF. 1. ed. São Paulo: Oficina de Textos, 2011. $166 \mathrm{p}$.

DNIT - DEPARTAMENTO NACIONAL DE INFRAESTRUTURA DE TRANSPORTES. Norma DNIT 035/2005-ES: Pavimentos flexíveis - microrrevestimento asfáltico a frio com emulsão modificada por polímero: especificação de serviço. 1. ed. Rio de Janeiro: IPR, 2005. 9p.

GUJAR, R.; CHAUHAN, K. A.; DADHICH, G. Microsurfacing - an eco-efficient tool for road safety and pavement maintenance. International Journal of Sustainable Construction Engineering \& Technology, v. 4, p.47-51, 2013.

KUMAR, R; RYNTATHIANG, T. L. New laboratory mix methodology of microsurfacing and mix design. Transportation Research Procedia, v. 17, p.488-497, 2016.

LABI, S.; LAMPTEY, G.; KONG, S. H. Effectiveness of microsurfacing treatments. Journal of Transportation Engineering, v. 133, p.298-307, 2007.

LUZZI, F. C. Análise do uso de material fresado como agregado no microrrevestimento asfáltico a frio (MRAF). Revista Especialize On-line IPOG, v. 1, p.01-16, 2017.

POURSOLTANI, M.; ATAOLLAHI, A.; HESAMI, S.; HESAMI, E. A review on micro surfacing mixture and perusing the feasibility of using recycled materials in it. Journal Management System, v. 25, p.87-100, 2017.

ROBATI, M.; CARTER, A.; PERRATON, D. Evaluation of a modification of current microsurfacing mix design procedures. Canadian Journal of Civil Engineering, v. 42, p.319-328, 2015. 